\title{
Analysis of commodity traffic in the European macro-region
}

\author{
German Danilin,' Sergey. Sokolov, and Tatiana Knysh \\ Admiral Makarov State University of Maritime and Inland Shipping, 5/7, Dvinskaya st., St. \\ Petersburg, 198035, Russia
}

\begin{abstract}
One of the key industries of any state is the transport industry. It plays a significant role in the development of the country's economy and ensuring its defense capability. Therefore, the development of the transport industry is always relevant for Russia with its vastness and climatic conditions. In this work, at the first stage, the country's cargo turnover by mode of transport is considered and the current state of the transport system, in particular, water transport, is analyzed. At the second stage, the concept of multimodal transportation is considered and the possibility of using multi-agent systems for automating management processes in water transport is being studied.
\end{abstract}

\section{Introduction}

One of the key industries of any state is the transport industry. It plays a significant role in the development of the country's economy and ensuring its defense capability. Therefore, the development of the transport industry is always relevant for Russia with its vastness and climatic conditions. In this work, at the first stage, the country's cargo turnover by mode of transport is considered and the current state of the transport system, in particular, water transport, is analyzed. At the second stage, the concept of multimodal transportation is considered and the possibility of using multi-agent systems for automating management processes in water transport is being studied.

\section{Cargo turnover statistics}

According to the research by the information and analytical agency SeaNews [1], over the past 2019, the transportation of goods by all types of transport in our country has grown, compared to the indicators of 2018 , by $1.7 \%$ and amounted to 8.3 billion tons. All this increase occurred only due to the growth of traffic volumes by road transport, which delivered $69 \%$ of the total traffic. At the same time, transportation by other modes of transport decreased. For railway and pipeline modes of transport, the reduction occurred at the level of $0.9-15.4 \%$ of the total volume was delivered by rail, and $13.98 \%$ of the total volume by pipeline. The volume of air traffic fell slightly more, which delivered $0.014 \%$ of the total, - for it, the drop was $1.1 \%$. The largest reduction was recorded in water transport. For inland waterway transport, it was $14.9 \%$, with a decrease to 98.8 million tons, corresponding to $1.2 \%$ of the total,

\footnotetext{
* Corresponding author: 1t.101@mail.ru
}

and for sea transport $-19.8 \%$, with a decrease to 18.5 million tons, corresponding to $0.22 \%$ of the total traffic. The ratio of the volume of cargo transportation by mode of transport in Russia is shown in Figure 1.

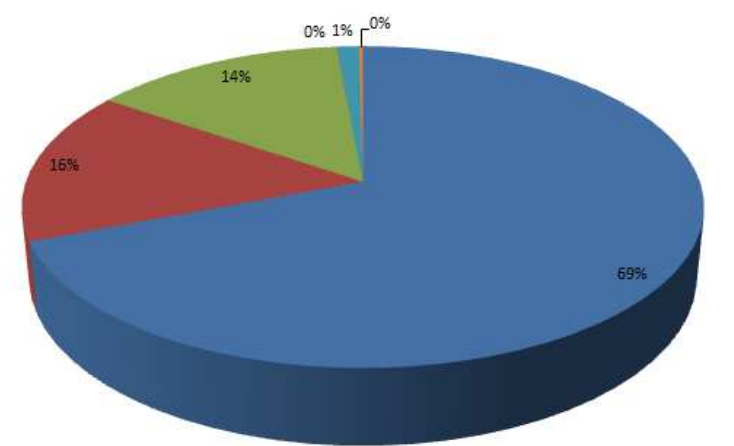

Figure 1. Ratio of freight traffic by mode of transport in Russia

For comparison, Figure 2 shows a similar ratio for 2017 for the EU countries [2]: 

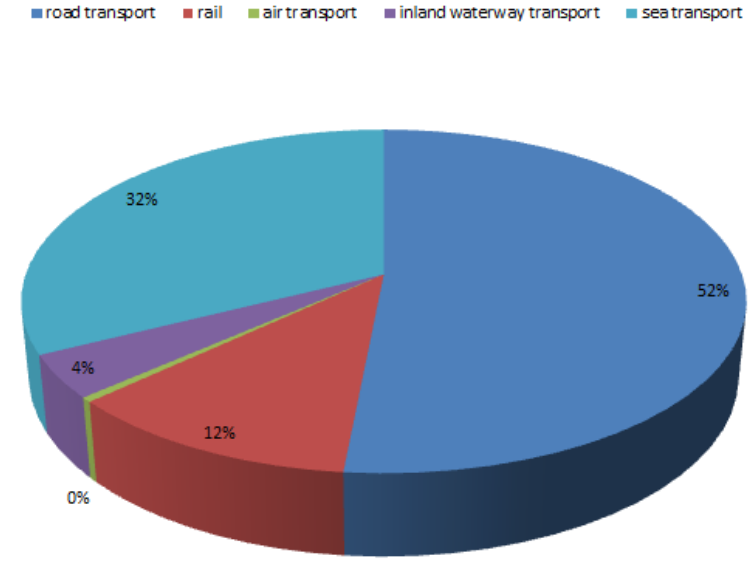

Figure 2. Ratio of freight traffic by mode of transport in EU countries

\section{Analysis of the state of the water transport system}

As can be seen from the diagrams presented in Figures 1 and 2 , in both cases, the leading mode of transport is automobile, the most lagging mode of transport is air, and transportation by rail accounts for an approximately equal share of the total volume. The most striking difference is the indicators of transportation by water transport. Their share in our country is much lower than that in the EU countries.

Most likely, this state of affairs is due to the fact that during the time of complications in the Russian economy in the 1990s, there were violations in the wellfunctioning system of cargo transportation using water transport, which resulted in a decrease in the volume of deliveries. An additional influence was exerted by the features of water transport:

- Low speed, usually within $25 \mathrm{~km} / \mathrm{h}$;

- The seasonal nature of navigation on the inland waterways of Russia.

As a result, transportation by road and rail gained great popularity, and water transport became unattractive for investment, which led to the development of the following number of problems [3, 4]:

- The amount of funds allocated from the federal budget for many years has been insufficient to maintain the structure of water transport.

- Inland waterways and navigable hydraulic structures on them are in the unsatisfactory condition, critically acceptable from the point of view of ensuring the safety of navigation.

- The fleet is in the unsatisfactory technical condition.

- The degree of development of the market for passenger transportation by water transport is not high.

It is obvious that the listed problems are interconnected with each other. Today, domestic shipping companies spend, taking into account the seasonality of shipping, up to $17 \%$ of their income on the maintenance of inland waterways. At the same time, in Germany and the USA (countries with year-round shipping), these shares are about 11 and $13 \%$, respectively. But due to insufficient state funding, there are not enough funds to maintain the structure of water transport. Only $31 \%$ of hydraulic structures currently comply with safety standards. The pace of repair and restoration work lags behind the progressive destruction processes, which increases the likelihood of man-made disasters and creates a threat of Russia's loss of a single deep-water system as a transport artery [5]. In addition, a common problem for all types of transport today is the degree of its deterioration, which is:

- $60 \%$ for rail;

- $50 \%$ for automobile;

- $50 \%$ for air;

- $34 \%$ for marine;

- $66 \%$ for inland waterways.

As you can see, the least worn-out in our country at the moment is sea transport, since it provides export, import and transit needs of the country and receives a larger volume of investments. The importance of inland waterway transport is clearly underestimated, and therefore it is the most worn out.

However, water transport has undoubted advantages [2]:

- For some hard-to-reach areas, it is the only mode of transport suitable for the delivery of goods.

- It is more environmentally friendly than road and rail. Specific carbon dioxide emissions from inland waterway transport are only $5 \%$ of vehicle emissions or $20 \%$ of railway emissions.

- The level of accidents in water transport (in monetary terms) is 14 times lower than the same indicator for road transport and 2 times lower than for rail transport.

- Indicators of its energy consumption, calculated according to the ratio "kilometer of track / ton of cargo", is about $17 \%$ of the indicators of road transport or $50 \%$ of the indicators of railway transport.

- Has a low cost of delivery of goods.

\section{Implementation of automation tools at water transport facilities}

The MSC concept assumes the organization of cargo delivery under one contract with the involvement of two or more different types of transport. This type of transportation also has a variety - intermodal transportation (IMT). The difference from MMT is that the cargo is transported in any intermodal unit, for example, a container, and directly in it is transferred from one mode of transport to another. The use of water transport within the framework of the MMP concept can have a beneficial effect on reducing the cost of transportation, the congestion of roads in densely populated areas and the total load exerted by transport on the environment. And for the further development of the MMT concept, an expansion of the network of terminal and logistics centers (TLC) is required [6].

TLC is a transport hub designed to combine and redirect freight flows delivered by various modes of transport, and to manage them. The condition for the 
effective operation of the TLC network is the wellcoordinated work of service services and all types of transport. To ensure the well-coordinated work of service services and transport, modern automated process control systems (APCS) [7] are needed. Such systems today can be created on the basis of multi-agent systems.

A multi-agent system is a collection of physical sensors that collect information and agents intellectualized software entities that act as analysts and decision makers. Multi-agent technologies allow abstracting specific problems of system management and formulating a solution for the current situation already at the level of abstraction. Thanks to the use of such systems, it has become possible in real time to coordinate among themselves control flows, work flows and information flows, as well as build interaction between all TLC services. In the work of V.I. Kiyaev [8], an example of organizing monitoring of the seaport operation using multi-agent technologies is considered. And in the work of Yu.M. Iskanderov, V.D. Gaskarov and V.I. Doroshenko [9] offers a multi-agent model of an integrated ship control system. The disadvantages of multi-agent systems include the fact that at the moment they are "able" to solve only "narrow" problems. So far, only humans are capable of solving unstructured problems under conditions of uncertainty.

The basis for the formation of TLC at the junction of water transport with its other types are river and sea ports [10]. Their performance depends on many components, such as:

- Efficiency of port calls. To enter the port, the vessel must provide the port with approach and arrival information containing many different documents. Usually the list of these documents is standard, but sometimes the ports request additional documents. To improve the efficiency of port entry operations, intelligent devices for real-time data exchange can be used [11]. With their help, packages with incoming and outgoing information will be able to be automatically generated and sent to the port, and the vessel will receive the necessary information about the port's operation: water level, minimum depth in the fairway, estimated date and time of the vessel's acceptance into the port and weather conditions.

- Speed of document flow. Today, it may take up to 24 hours for the execution and signing of the package of transport documents by the responsible persons at the end of cargo operations, which is the reason for an additional delay in the dispatch of ships. The use of electronic document management systems should facilitate the acceleration of document circulation [12];

- Speed of loading and unloading operations;

- Productivity of warehouse operations.

The experience of the Chinese port of Qingdao, one of the five largest ports in China, can be cited as an example of the successful implementation of automation tools to increase the speed of loading and unloading operations and increase the productivity of warehouse operations. Since 2017, the port has been operating around the clock, seven days a week and with minimal human intervention. All processes in the port are automated, and trucks, cranes and loaders are represented by drones powered by electric traction. The technique itself monitors its condition and requires the presence of a person only in emergency situations. As a result of the introduction of automation equipment, the port's cargo turnover increased by $20 \%$ in two years. China managed to achieve the desired effect, but when carrying out full automation, its negative sides were also revealed, which must be taken into account when automating Russian ports.

Perhaps the main disadvantage of full automation is that it involves the reduction of a huge number of workers. The second disadvantage is the cost of carrying out such an action plan. Therefore, it is so important to pay significant attention to planning processes to mitigate negative manifestations. The Port of Los Angeles was unable to replicate the success of Qingdao's automation precisely because of scheduling problems.

For newly built ports, comprehensive automation can and should be provided at the design stage [13, 14], but among the currently existing Russian river ports, a significant part is privately owned and operates at its own expense. In the context of the need to comply with safety standards, a small volume of orders and a high depreciation of fixed assets, such ports are not able to afford full automation, since it will be very costly for them, and maybe even destructive. In this case, partial automation is more cost-effective: replacing outdated portal cranes with mobile harbor cranes (MPC), introducing automatic bridge stackers, reachstackers and smart warehouses.

As mentioned above, modern APCS are necessary to ensure the coordinated work of service services and transport, and over time there will be a need to coordinate with each other many different APCS that manage different infrastructure facilities and different modes of transport from different regions. A promising way to solve this problem is to combine the sets of APCS within the framework of intelligent transport systems (ITS).

ITS is a control system that integrates modern information and telematic technologies and is designed for automated search and acceptance for implementation of the most effective scenarios for managing the transport and road complex of a region, a specific vehicle or a group of vehicles in order to ensure a given mobility of the population, to maximize indicators of the use of the road network, improving the safety and efficiency of the transport process, comfort for drivers and users of transport [15].

The unification of the APCS within the ITS will make it possible to unite unmanned motor vehicles, unmanned vessels, the TLC network and automated ports with the help of various wireless technologies, such as WiMAX, 5G and radio communication, and the use of developments in the field of embedded systems will make it possible to widely use real time and achievements in the field of artificial intelligence to improve the efficiency of road transport infrastructure by reducing the number of road congestion, travel time, fuel 
consumption and, as a consequence, air pollution with hazardous emissions [16].

In addition, the integration of information flows from meteorological services, bridge opening systems, parking systems, vehicle registration plate recognition systems and video surveillance systems will dynamically redistribute traffic, which will have a beneficial effect on traffic safety.

With such a high level of automation, of course, the issue of ensuring a set of measures for information security requires special attention [17-19]. The problem is relevant both for the means of electronic document management and port automation, which have various vulnerabilities, and for unmanned navigation. In 2015, at the Black Hat USA conference, Synack researcher K. Moore presented a report on the safety of Globalstar GPS tracking systems. The network underlying Globalstar does not provide mechanisms for authentication and encryption of transmitted data, and the mechanism of simplex data transfer does not provide for the possibility of their validation. When checking satellite terminals used in shipping, vulnerabilities were also found: devices mainly use unprotected and sometimes undocumented protocols, accounts configured by default provide the ability to reset passwords and use backdoors.

An example was the experiment on compromising satellite systems, implemented by students at the University of Texas in July 2013. In the course of this experiment, researchers using an inexpensive and readily available GPS signal simulator managed to compromise the satellite signal, and then deflect an expensive yacht off course, forcing it to accept the signals of a real satellite for interference.

Thus, if the necessary attention is not paid to cybersecurity issues in water transport, then the role of the main cause of accidents in water transport will shift from the human factor [20] to IS threats, as evidenced by the results of the above experiment.

\section{Conclusion}

Today, in the World Bank's ranking, compiled on the basis of the International Logistics Performance Index (LPI), Russia lags behind Germany, Sweden, Belgium, Singapore, the Netherlands and the UK. The reasons for this lag lie in the fact that at the moment the water transport system in Russia is characterized by a complex of problems that require decisive measures, and one of the main problems is the low degree of automation at water transport facilities: LPI, which takes into account many criteria and shows the degree of innovative development of the country, indicates that Russia lags behind the leading countries in the intensity of the use of innovative and technical solutions, the use of resourcesaving technologies, the use of electronic automated solutions. The use of unmanned vehicles also remains at a minimum.

However, Russia has a very good potential to reduce the gap in these indicators, since, due to its geographical location, it has a large number of large ports capable of providing a significant total volume of cargo turnover. The implementation of the advantages of inland waterway transport when using it within the framework of the MMT can contribute to the increase in the efficiency indicators of the transport and logistics system and to unlock this potential. In addition, to improve the MMT concept, in turn, it is required to accelerate the pace of innovative development of the TLC network due to the wider use of automation tools.

It is not yet possible to completely replace a person by means of automation, since only he is still capable of making non-standard decisions and solving unstructured tasks, therefore, routine processes and hard physical labor primarily require automation. At the same time, for already existing ports, selective automation is more economically profitable and less destructive, in particular, unmanned vehicles, modernized transshipment equipment, smart warehouses or automated terminal operation systems can be introduced, while for newly created ports full automation should become the norm.

An important aspect when carrying out automation, which requires consolidation at the legislative level, is the provision of a set of measures for information security.

\section{References}

1. Freight turnover of Russian transport Retrieved from: https://seanews.ru/2020/02/03/rugruzooborot-rossijskogo-transporta-17/

2. G. I. Shepelin and A. I. Skryabina Symbol of science: international scientific journal, 3, 53-57, (2020)

3. M. V. Grachev Problems and prospects of transport logistics in inland waterway transport Retrieved from: https://cyberleninka.ru/article/n/problematika-iperspektivy-transportnoy-logistiki-navnutrennem-vodnom-transporte/viewer

4. S. Sokolov, N. Glebov, R. Novoselov and S. Chernyi MATEC Web of Conferences, 239(6), 03004, (2018)

5. L. P. Gvozdareva, N. I. Mamaeva Actual problems of modern economic science: Materials of the $X$ International Scientific Conference (Astrakhan) (2020)

6. V. V. Tsyganov, S. A. Savushkin and V. A. Borodin, ITNOU: Information technologies in science, education and management, 4, 34-39, (2019)

7. E. Koroleva, S. Sokolov and E. FilatovaE3S Web of Conferences, 138, (2019)

8. V. I. Kiyaev, 2019 Actual problems of the development of modern science: theory and practice (St. Petersburg) (2018)

9. Yu. M. Iskanderov, V. D. Gaskarov and V. I. Doroshenko, Bulletin of the State University of Marine and River Fleet named after Admiral S O Makarov, 11(5), 831-841, (2019) 
10. E. Koroleva, S. Sokolov, I. Makashina and E. Filatova, E3S Web of Conferences, 203, (2020)

11. A. A. Klimov, V.P. Kupriyanovsky, V. V. Alenkov et al. International Journal of Open Information Technologies, 3, 75-91, (2020)

12. A. P. Nyrkov, S. S. Sokolov, A. S. Karpina et al. International Journal of Engineering and Technology (UAE), 7(1), 39-43.

13. E. Koroleva, S. Sokolov, I. Makashina and E. Filatova E3S Web of Conferences, 138, (2019)

14. A. Nyrkov, A. Shnurenko, Sokolov S. et al. 1 International Journal of Electrical and Computer Engineering 7(6) 3578-3582 (2017)

15. GOST $\mathrm{R}$ 56829-2015 Intelligent transport systems. Terms and definitions Retrieved from: http://docs.cntd.ru/document/1200128315

16. V. Reshnyak, S. Sokolov, A.Nyrkov and V. BudnikJournal of Physics: Conference Series 1015(4), (2018)

17. S. S. Sokolov, O. M. Alimov, Y. A. Trubacheva et al. Proceedings of the 2018 IEEE Conference of Russian Young Researchers in Electrical and Electronic Engineering, ElConRus 2018, 132135, (2018)

18. S. S. Sokolov, O. M. Alimov, L. E. Ivleva et al. Proceedings of the 2018 IEEE Conference of Russian Young Researchers in Electrical and Electronic Engineering, ElConRus 2018, 128131, (2018)

19. S. S. Sokolov, O. M. Alimov, M. G. Golubeva et al. Proceedings of the 2018 IEEE Conference of Russian Young Researchers in Electrical and Electronic Engineering, ElConRus 2018, 124127, (2018)

20. M. A. Kirilov and A. I. Rozhko Bulletin of the Astrakhan State Technical University. series: marine engineering and technology, 3, 16-22, (2020) 